\title{
Nota del editor
}

\section{Perspectivas actuales en didáctica de la literatura}

\author{
Felipe Munita \\ Universitat Autònoma de Barcelona y Universidad Católica de Temuco
}

(Texto recibido el 30 de septiembre de 2019; aceptado el 30 de septiembre de 2019) DOI: https://doi.org/10.5565/rev/jt13.853

Hace ya casi 25 años, en un texto que podría considerarse fundacional para el desarrollo de la didáctica de la literatura en el ámbito hispanohablante, Teresa Colomer sintetizaba las principales líneas de renovación que venían gestándose en los años ochenta y principios de los noventa para pensar el avance hacia un nuevo modelo de enseñanza de la literatura en la escuela. Así, el modelo denominado de "educación literaria" que comenzaba a configurarse en esos años parecía estructurarse sobre la necesidad de favorecer el acceso directo de los estudiantes a las obras (mediante una diversidad de actividades y modalidades de lectura), la intención de ayudar al alumnado en el progresivo avance de su competencia de comprensión e interpretación de textos literarios, y la intención de explorar nuevas formas de programación que, más allá de acumular contenidos sobre literatura, constituyeran verdaderos itinerarios de aprendizaje literario durante la escolaridad obligatoria (Colomer, 1996).

Cabría entonces preguntarse cuáles han sido las líneas de investigación que han surgido y se han consolidado desde aquel entonces. Esta pregunta pone el acento en el tipo de conocimiento que ha construido la didáctica de la literatura en estas dos primeras décadas del nuevo siglo, periodo en el que se han observado ingentes avances en su proceso de consolidación como campo científico.

Sin ánimo alguno de exhaustividad, destacaremos a continuación tres focos de estudio que, desde nuestra perspectiva, han sido particularmente relevantes en estos lustros, en especial en el contexto hispanohablante. El primero de ellos, que puede leerse como un derivado del intento por favorecer el contacto directo del alumnado con las obras, es el interés de los didactas por atender al lector "real" (y no solo "implícito") propio de las situaciones escolares de lectura. Esto ha llevado a un progresivo avance en ámbitos de estudio como por ejemplo el de las "respuestas lectoras", que contaba ya con una importante tradición en la investigación anglófona, o el del "sujeto lector", concebido a principios de este siglo desde la didáctica francófona para explorar las particulares formas de apropiación que cada sujeto hace de los 
textos leídos. Los trabajos desarrollados en este ámbito han ofrecido información relevante para ampliar nuestra comprensión de lo que sucede "internamente" cuando los niños y jóvenes se implican en la lectura de obras literarias, especialmente en situaciones de mediación diseñadas e implementadas en contexto escolar.

Un segundo foco ha sido la atención al corpus literario. Este ámbito, situado en un terreno de confluencia entre la didáctica de la literatura y los estudios en literatura infantil y juvenil, ha derivado en investigaciones acerca de cómo los libros para niños y jóvenes "enseñan a leer" a sus lectores. Recordemos que una de las líneas de renovación de la nueva didáctica era favorecer el avance en la competencia interpretativa; ergo, uno de los movimientos para atender a ello fue constatar la dificultad de formar lectores literarios expertos (por ejemplo, atentos a los efectos expresivos que tienen determinados recursos utilizados en las obras), si los propios formadores adultos nunca llevábamos la atención a los aprendizajes literarios que esas obras nos ofrecen. Lo anterior llevó a hacer descripciones cada vez más detalladas y profundas del corpus infantil y juvenil, y a pensarlo como una "escalera con barandilla" (Colomer, 2005) en la medida en que las obras ofrecen a sus lectores un itinerario de aprendizajes literarios cuya progresiva apropiación permite hacer lecturas cada vez más complejas de ellas.

El tercer foco son los docentes que actúan como mediadores entre los lectores y las obras. La intención de renovar los ejes que tradicionalmente había tenido la programación literaria en la escuela suponía contar con docentes capaces de construir sus propios itinerarios de lectura, a partir tanto de una selección personal del corpus como de una delimitación de los saberes y quehaceres del lector que serían movilizados en el contacto con esas obras. Esto derivó en diversos estudios realizados en el contexto de la formación inicial docente, muchos de los cuales alertaron sobre las deficiencias de los espacios de formación universitaria para ayudar a los futuros profesores a construir esos saberes. A su vez, y como respuesta a esa constatación, este nuevo conocimiento ha favorecido la puesta en marcha de procesos de innovación al interior de la formación docente que, esperamos, tengan un importante desarrollo en los próximos años.

Ahora bien, los tres artículos de investigación que recoge el presente volumen se sitúan, precisamente, en las tres grandes líneas de trabajo dibujadas en estas líneas. El primero de ellos pone el foco en el lector, y constituye un buen ejemplo de aquellos trabajos de vertiente etnográfica que tanta importancia han tenido en la investigación educativa de las primeras décadas de este siglo. Su autora, Daniela Cavalli, presenta un estudio de caso que analiza las respuestas lectoras de tres estudiantes de educación secundaria a textos poéticos, a partir de 
procesos de mediación docente y de conversación sobre esos textos en el espacio escolar. La escasez de estudios sobre respuestas lectoras a la poesía hace de este un texto particularmente interesante para quienes se interesan por la educación poética en las aulas. El artículo refuerza la necesidad de una educación literaria que tome en consideración la apropiación subjetiva y emocional que un lector hace de los textos que lee, y la reflexión acerca de cómo lo anterior puede conectar con los procesos de interpretación de textos literarios en las aulas.

El segundo texto, firmado por Lucas Ramada Prieto y Celia Turrión Penelas, focaliza en el corpus, específicamente en las obras de ficción digital para niños y jóvenes. Así, anclado en los estudios sobre lo que las obras ofrecen para la formación lectora y literaria de los alumnos, el artículo presenta interesantes líneas de reflexión acerca de los procesos de selección de obras digitales basados en la identificación tanto de los rasgos definitorios de la literatura infantil digital como de las principales dificultades interpretativas que las obras pueden provocar. En ese marco, los autores primero relevan ciertos desajustes y distancias que a menudo existen entre el lector implícito proyectado en las obras y el lector "real" que las lee; posteriormente, proponen una serie de acciones focalizadas en la superación de esas dificultades de lectura. Estamos, pues, frente a un buen ejemplo de construcción de itinerarios de aprendizaje ficcional articulados con una clara intencionalidad didáctica; en este caso, ayudar al alumnado a progresar en su competencia como lecto-usuarios de los nuevos corpus de ficción digital.

El tercer estudio lleva su atención al mediador. Mariana Valencia Leguizamón y Neus Real nos presentan una investigación realizada a partir de una experiencia de formación inicial docente centrada en la lectura de álbumes ilustrados. Su artículo se basa en la comparación de las valoraciones literarias que los futuros mediadores realizan antes y después de una formación específica en literatura infantil, concretamente sobre un álbum ("Un día diferente para el señor Amos", de Philip y Erin Stead) que ha tenido un amplio reconocimiento al interior del sistema literario para niños. ¿Cómo son leídas esas obras de calidad cuando llegan a manos de los mediadores?, es la pregunta que emerge de estudios como este. El texto muestra que esa lectura es muy diferente cuando se ha cursado una formación literaria específica, y pone de manifiesto la incidencia que puede tener esa formación en las posibilidades de valoración de textos por parte del futuro profesorado.

El volumen también incluye dos textos que se sitúan en una perspectiva más global acerca de la didáctica de la literatura. El primero es de la autora invitada de este número, Ana María Margallo, profesora e investigadora de la Universidad Autónoma de Barcelona y 
coordinadora del grupo "Gretel” de la misma universidad. En su texto, la Dra. Margallo recupera una de las principales marcas de identidad de cualquier didáctica disciplinar: la de ser disciplinas de intervención, cuya construcción de conocimiento debe pensarse en estrecha vinculación con la práctica educativa. Desde esa perspectiva, propone un itinerario en el cual presenta investigaciones realizadas por el grupo "Gretel", pero articulándolas con aquella dimensión de divulgación y de formación que está a la base de su conformación en tanto equipo de investigación en didáctica de la literatura. Y lo hace atendiendo a los dos grandes núcleos de trabajo del grupo: los estudios sobre literatura infantil y juvenil, por una parte, y la investigación sobre educación literaria, por otra.

El segundo es una entrevista con Yves Reuter, profesor emérito de la Universidad de Lille 3, fundador del grupo "Théodile” y uno de los principales referentes de la didáctica de la lengua y la literatura en el ámbito francófono. En la primera parte, el Dr. Reuter ofrece una aproximación a ciertos conceptos y definiciones que, desde su perspectiva, son centrales para entender la didáctica de la lengua y la literatura en tanto disciplina científica que construye conocimiento teórico sobre los procesos de enseñanza y aprendizaje de contenidos lingüísticoliterarios en contexto escolar. Posteriormente, presenta algunas líneas de reflexión sobre la didáctica de la literatura como campo específico, abordando así temas tan diversos como el lugar de la literatura en las aulas, los saberes a enseñar en el ámbito literario o la formación de los docentes encargados de enseñarlos, entre otros.

Asimismo, el volumen incluye una reseña del reciente libro "Narrativas literarias en educación infantil y primaria" (autoría de Teresa Colomer, Mireia Manresa, Lucas Ramada Prieto y Lara Reyes López, del grupo Gretel). La reseña, escrita por Karla Fernández de Gamboa Vázquez, sintetiza con claridad y precisión las principales aportaciones de un libro que, por su carácter divulgativo y práctico, parece de fértil entrada a los procesos de formación inicial de los docentes que actuarán como mediadores de lectura en las aulas de Infantil y Primaria.

Un apunte a modo de cierre: como puede colegirse de la diversidad de los trabajos aquí presentados, el presente número no se ha estructurado como un volumen "monográfico", en la medida en que no se centra exclusivamente en una determinada línea de investigación sobre educación literaria. Más bien, ha sido pensado como un número especial que aborda diversos temas vinculados a un campo científico común: el de la didáctica de la literatura. Lo anterior nos permitía ofrecer una fotografía de conjunto acerca de algunas líneas de investigación (sobre lectores, obras y mediadores) que han sido especialmente relevantes en este ámbito de estudio. 
Un ámbito que, si bien a día de hoy se asume como un campo específico al interior de la didáctica de la lengua (Dufays, 2007), con su propio conjunto de saberes teóricos, preguntas de investigación, actores y redes de estudio, todavía debe continuar afianzándose, especialmente en el particular contexto académico que conforman los países de habla hispana.

Agradecemos, finalmente, a los editores de la revista por su excelente acogida a la propuesta de este número especial, así como a las y los investigadores que participaron como pares evaluadores, por su lectura atenta y minuciosa de unos textos que, a partir de ahora, esperamos encuentren a muchos otros lectores interesados en la educación literaria de nuestros niños y jóvenes.

\section{Referencias}

Colomer, T. (1996). La didáctica de la literatura: tema y líneas de investigación e innovación. En C. Lomas (coord.), La educación lingüística y literaria en la enseñanza secundaria (pp. 123-142). Barcelona: Horsori.

Colomer, T. (2005). Andar entre libros. La lectura literaria en la escuela. México DF, Fondo de Cultura Económica.

Dufays, J. L. (2007). Du sens à l'évaluation, en passant par l'utilité. Actualité et enjeux d'une problematique de recherche. En J. L. Dufays (ed.), Enseigner et apprendre la littérature aujourd'hui, pour quoi faire? (pp. 7-15). Louvain-la-Neuve: Presses Universitaires de Louvain.

\section{Créditos}

Las ilustraciones de las portadas de cada número han sido diseñadas por estudiantes de EINA (Escola de Disseny i Art, Barcelona), que cursan el posgrado Il·lustració Creativa, bajo la dirección de Sonia Pulido, profesora de Ilustración para Prensa.

\section{Revisores para el Volumen $\mathbf{1 2 . 3}$}

El editor desea agradecer a los siguientes revisores su contribución a la preparación del volumen 12.3:

Ana Albuquerque e Aguilar (Universidade de Coimbra), Giselly Lima de Moraes (Universidade Federal da Bahia), Claudio José de Almeida Mello (Universidade Estadual do CentroOeste), Daniela Maria Segabinazi (Universidade Federal da Paraíba), Silvana Gili (Universidade Federal de Santa Catarina) 
Información sobre el autor:

Felipe Munita es Doctor en Didáctica de la Lengua y la Literatura. Profesor e investigador en los ámbitos de mediación de la lectura, educación literaria y poesía para niños y jóvenes. Actualmente es profesor visitante en la Universidad Autónoma de Barcelona, donde forma parte del grupo GRETEL, e investigador asociado del CIED de la Universidad Católica de Temuco.

E-mail: fmunita@gmail.com

Para citar este artículo:

Munita, F. (2019). Nota del editor: Perspectivas actuales en didáctica de la literatura. Bellaterra Journal of Teaching \& Learning Language \& Literature, 12(3), 1-6. DOI: https://doi.org/10.5565/rev/jt13.853 